\title{
Book Review \\ Responsible Corporate Strategy in Construction and Engineering. Doing the Right Thing?
}

by Martin Loosemore and Florence Phua, published by Spon Press: ISBN 978-0-41545910-5. AUD 69.95.GBP 35.00, 192 pages.

It is often said that the practice of management in the architectural, engineering, and construction (AEC) sector is highly derivative, that attempts to distinguish it as a separate and distinct area of professional practice are erroneous, and that the best prescription for its low productivity is to imitate best practice from the manufacturing industry - Egan can't be wrong, can he? Loosemore and Phua are both respected writers on the issues facing the industry and its members. They have conceived this timely book from the standpoint that slavish and unquestioning imitation of mainstream corporate social responsibility (CSR) strategy formulation and implementation is likely to result in poor quality decision-making and disappointing outcomes.

Using a wide range of authoritative sources the authors first introduce the concept of CSR with all its attendant facets, make a compelling case for its centrality to corporate strategic planning, explain the consequences that this inevitably imposes on the governance of a firm or corporation, and then outline the ethical consequences this has for them both internally and externally. It is probably inaccurate to characterise the authors' presentation of their case as left versus right, green versus un-green, or idealistic versus cynical, but a sense is gained of an ongoing dialogue between competing polar extremes throughout the first four chapters, which remind adherents or enthusiasts of a particular camp of their social and business obligations to the opposing viewpoint. In many respects this is both refreshing and liberating, allowing readers of a particular persuasion to "come out of the closet", clad in the armour of a sound business case.

Arguably the most important feature of this book is that the first four chapters are followed by a fifth, containing nine case studies of AEC organisations. Predictably they include major design and engineering consultancies, developers and contractors, but usefully they also include smaller firms from lower tiers within the construction industry supply chain. Each of the cases is presented in a highly structured format, reflecting the way in which each was conducted. However it is not always clear whether the case being reported reflects a single interview with a key stakeholder in the organisation, or whether it is in fact a digest of multiple interviews. It would also have been useful to provide clearer visual separation between each case, for instance starting each one on a new page. Nevertheless these are minor quibbles and the authors draw the book to a useful conclusion making cogent generalisations from the case studies about the challenge of designing and implementing CSR for a range of different types of organisation.

As with any well researched and well written addition to the AEC library the authors are to be commended for their efforts, if for no other reason than to give lie to the notion that the field is indeed derivative. In this case the commendation goes much further as the book deserves a place on the sentient practitioner's bookshelf.

Graham Brewer

Associate Professor

University of Newcastle 